\title{
EDITORAL
}

\section{RBCE: PLURALIDADE, ABRANGÊNCIA}

O presente número traz como importante marco o equilíbrio entre perspectivas teórico-metodológicas, com um número quase que equivalente entre artigos oriundos de pesquisas das Humanidades e das Ciências da Vida. Isso reflete tanto a pluralidade da área, quanto o esforço da RBCE em refleti-la em suas páginas. Ao mesmo tempo, mostra a credibilidade e respeitabilidade que o periódico alcança nos diferentes setores da educação física/ciências do esporte.

O primeiro trabalho deste número analisa material de imprensa sobre as Copas do Mundo de futebol de 1958 e 1962, comparando-o com os escritos sobre a Copa de 2002, a fim de explicitar possíveis descontinuidades no tratamento desses eventos esportivos. O seguinte reflete sobre o processo de construção da masculinidade no campo esportivo e a percepção do envelhecimento a partir de discursos produzidos pela mídia escrita e das lembranças e esquecimentos de atores que presenciaram e/ou escreveram sobre a Copa do Mundo de 1950. Em diálogo com o historiador alemão Reinhart Koselleck, o artigo subsequente apresenta apontamentos sobre as contribuições da história dos conceitos para as investigações que têm como objeto as práticas corporais institucionalizadas, entre as quais, o esporte. A partir de uma abordagem histórica, o texto seguinte indica possíveis caminhos para se pensar acerca da inserção dos esportes de ação no Brasil, tomando como referência principal a prática do skateboard. $\bigcirc$ artigo seguinte problematiza o papel do Colégio Brasileiro de Ciências do Esporte (CBCE) e apresenta posições acerca de possibilidades comunicativas importantes para um cenário como o do CBCE, pensando-o como um "solo comum" para diferentes comunidades que se relacionam, direta ou tangencialmente, com o campo da educação física. Sucede-se um estudo etnográfico de dois casos de inserção da educação física no cotidiano de duas escolas públicas, que busca compreender que tipo de culturas de educação física têm sido criadas nessas instituições. Na sequência temos um trabalho advindo da Argen- 
tina, que aborda a educação física nas políticas socioeducativas destinadas aos jovens numa perspectiva comparada entre programas que se desenvolvem naquele país e no Brasil. Ainda numa análise comparada, o artigo seguinte trata da precariedade da educação física escolar ao lado do quadro de crescimento das políticas públicas de esporte e lazer e de projetos sociais esportivos no Brasil. O trabalho ulterior focaliza a percepção de atletas profissionais de basquetebol masculino quanto ao estilo de liderança de seus técnicos a partir da aplicação do questionário denominado Escala de Liderança Revisada para o Esporte. A avaliação do conhecimento nutricional de mulheres fisicamente ativas e sua associação com o estado nutricional é o tema abordado no trabalho seguinte. Proveniente da Itália, o texto posterior investiga o efeito de uma sessão de exercícios na modificação da imagem corporal segundo a Escala de Estados de Imagem Corporal (BISS). Em seguida, temos trabalhos que discutem resultados de pesquisas que relacionam a ação do hormônio leptina e desregulações no sistema reprodutório durante a puberdade em atletas de ginástica artística do sexo feminino; dos efeitos de altas doses de cafeína na resistência óssea à fratura em ratas jovens submetidas a treinamento de saltos verticais; dos efeitos do treinamento de força especifico no desempenho de nadadores velocistas; e do desempenho isocinético da musculatura extensora e flexora do joelho em atletas de futsal nos membros dominantes e não dominantes. Fechando a edição, temos uma resenha sobre o livro Futebol e globalização, organizado por Luiz Carlos Ribeiro e publicado em 2007.

Este número marca a despedida de Marcus Aurélio Taborda de Oliveira da equipe editorial da RBCE. Saudamos sua importante contribuição, bem como o prosseguimento do apoio que destina ao periódico, cujo projeto alcança um patamar bastante importante agora, quando foi reconhecido e aceito pela Scielo (Scientific Electronic Library Online). Comemoremos. Sigamos.

Alexandre Fernandez Vaz Marcus Aurélio Taborda de Oliveira 